\title{
APPLICATION OF ACOUSTIC EMISSION METHOD FOR THE EVALUATION OF THE MICROMECHANICS OF DESTRUCTION OF FIBERGLASS MATERIALS UNDER STATIC LOAD
}

\author{
Margarita URBAHA (D) ${ }^{1}$, Konrad STEFAŃSKI (D) ${ }^{2}$, Mukharbiy BANOV (i) ${ }^{3}$, *, \\ Vladimir SHESTAKOV (D) 4 \\ 1, 3, ${ }^{4}$ Department of Transport systems and logistics, Institute of Aeronautics, Riga Technical University, Riga, Latvia \\ ${ }^{2}$ Kielce University of Technology, Faculty of Mechatronics and Mechanical Engineering, Kielce, Poland
}

Received 13 January 2020; accepted 16 April 2020

\begin{abstract}
The paper presents the results of experimental studies using the acoustic emission method of samples made of fiberglass, the design feature of which is the presence of both base fibers and weft fibers. The test data are presented in relative units and the concept of staged damage accumulation is used, which allows one to recognize subtle phenomena of the nature of the destruction of fiberglass. Tests of the samples with a transverse arrangement of fibers with respect to the applied load showed that the fracture process both in the strain parameters and in the parameters of the total acoustic emission has two stages of damage accumulation: the stage of proportional change of these parameters from stress and the stage of intensive increment of these parameters. In this case, the parameter of the total acoustic emission shows that this process of destruction begins earlier by $5-6 \%$ than the strain parameter shows. The proposed methodology and equipment allows us to identify the nature of fracture and assess the tensile strength of such a "staged" composition, and also to solve the problem of what affected the structural unity violations, which may be due to the presence of a set of cracks formed during manufacturing or under the influence of stresses and the external environment during the process of loading.
\end{abstract}

Keywords: acoustic emission, safety of constructions, deformation, composite materials, composite structures, composite fibers and matrix, polymers, stiffness, specific viscosity, heat resistance.

\section{Introduction}

The use of fibrous composite materials in aircraft construction is treated with great caution because of the need to ensure a high level of object reliability. They are developed to improve such mechanical properties as strength, specific strength, stiffness, specific viscosity, heat resistance. The composite consists of a base (matrix) in which a strengthener in the form of fibres or dispersed particles is distributed with a certain pattern. There are composites with two types of matrices: a metallic base and a polymer base. Thus, for example, metal-based composites reinforced with ceramic fibres have high heat resistance and comparatively low specific weight, and they have higher fatigue strength when compared to traditional alloys. Their temperature capability (a ratio of the temperature, at which tensile strength is $14 \mathrm{kgf} / \mathrm{mm}^{2}$, to the melting temperature) is $0.80-0.98$. Polymer-based composites reinforced with carbon fibres simultaneously possess low density (up to $3 \mathrm{~g} / \mathrm{cm}^{3}$ ), a high modulus of elasticity $\left(15,000-20,000 \mathrm{kgf} / \mathrm{mm}^{2}\right)$ and a low linear expansion coefficient $\left(2-5^{\star} 10-6 \circ \mathrm{C}-1\right)$, and have a comparatively low cost. They have a high stiffness-to-weight ratio and strength in reinforcement direction. Traditional alloys cannot have such a combination of properties. In fibre composites, the main purpose of fibres is to withstand the load, whereas the matrix transfers the load to fibres and distributes it among them. Consequently, the mechanical properties of a composite, in the first place, depend on the properties of its fibre and matrix. In this case, the transfer of stresses from the matrix to the fibre occurs through the matrix-fibre interface; and the issue of the nature of bonding on the matrix-fibre interface is one of the most important and poorly studied... In addition to that, the strength of fibre compositions depends on the volume of fibre content. The strength changes in linear fashion at the concentration of fibres of 5 to 80 percent.

${ }^{*}$ Corresponding author. E-mail: muharbij@inbox.lv 
At a concentration of above 80 percent, it is already impossible to impregnate and wet all fibres with matrix, which deteriorates the ability of the matrix to redistribute stresses and fully transfer the load to fibres. Eventually, the strength and loading capacity of the whole composition are determined by the condition of fibre-matrix interface, the nature of fibre-matrix adhesion and resulting bonds. In turn, the optimum behaviour of a composite depends on the "structural unity" of its components, which presumes good adhesion of all elements of the strengthener and matrix with a neighbouring element. Such an adhesion ensures a uniform transfer of forces from component to component as well as their deformation as a single structural unit. Compositions that ensure the above mentioned structural unity are considered as ideal or "model", for example, compositions with parallel fibres stretching along the fibres. The objective of this research is to reveal the nature of failure and theoretically evaluate the ultimate strength of a "model" composition like this, as well as to solve the issue regarding the factors that have affected the structural unity, which can be conditioned by the presence of a totality of cracks appearing in the process of manufacturing or under the effect of stresses and external environment during loading. For example, compositions consisting of strong plastic fibres and a plastic matrix, which bond well with one another, usually fail due to plastic flow instability. In another case, the strength of a composition depends on the combination of the ultimate strengths at the tension of the fibres and matrix and the ultimate shear strength of the matrix. In both cases, the strength of the fibres and matrix is quantitatively reproduced and determined by the plastic properties of the both materials. At the same time, the strength of each material has minimal scatter. Thus, the strength of such a "model" composition can be expressed through the mean strengths of the fibres and matrix and the volume content of the components of the compositions. The analysis of properties of such compositions presumes the simplest possible account of several important parameters, notably the volume fraction of fibre length and the value of fibre length-to-diameter ratio for finite length fibres. This analysis serves as a good starting point for describing the behaviour of a composition based on the mean strength of fibres. The gist lies in analysing the behaviour of a composition at tension (the strength and failure of "model" compositions reinforced with fibres possessing similar strength). The behaviour of a composition becomes much more complex if it contains a combination of brittle fibres (for example, glass fibre) with a large scatter of tensile strength and a semibrittle matrix (for example, epoxy resin). The process of failure in this case is represented by the accumulation of a critical number of broken fibres, which eventually, in an alternating sequence, spread parallel to fibres making the crack propagate either in the matrix or on the matrixfibre interface perpendicular to fibres, which leads to the formation of torn edges. In the strength theories of such compositions, a static characteristic of fibre strength and a criterion of the critical accumulation of broken fibres based on the analysis of bundle strength are used. A relation is established between the statistical nature of fibre strength and the strength of a composition as a whole. This task was first considered by Parratt (1960) who assumed that the failure of a composition occurs at the moment when the accumulating failure of the fibres leads to a shear failure of the matrix and a further increase of load cannot be transferred to other fibres because the ultimate shear strength of the matrix has been reached. Both technical and economic efficiency of using composite materials largely depend on their strength, rigidity and integrity under specified operating conditions throughout the entire service life. It should be noted that the wider use of composites is limited due to the lack of accurate knowledge about their durability and variable mechanical properties under various operating conditions (Mortensen, 2007; Myers et al., 2007). However, the use of these materials and the high requirements for reliability and required safety factors reaching value of 1.5 in accordance with the US aviation regulations of the Federal Aviation Administration (FAR $₫$ 25.303) (Shanley, 1962) in aviation and astronautics have determined the particular importance of non-destructive testing in these industries.

Nowadays there are many theoretical models of compositions in such materials, but for the most part they simplify the real material and are intended only to describe the phenomenon from a qualitative point of view. Therefore, experimental methods take a special place in controlling the fracture process and predicting durability, which allow, based on some model ideas about fracture mechanisms and rapid testing of samples, to control fracture of materials and provide a reliable estimate of the durability of products made of composites under different operating conditions.

Specialists are expected to determine the method for control of reliability of composite materials and its condition during operation in more dangerous places. To determine the frequency of inspections, it is necessary to have durability characteristics during operation and accumulation of surfaces, which is problematic for composites. Therefore, in this case, the energy accumulation velocity of acoustic signals of acoustic emissions corresponding to dangerous sections during the service load cycle was used. At the same time, the experimental methods used to study the mechanics of composites, such as the photoelasticity method, the tensometric method, the Moire method, and holography, for example, paper (Paramonov \& Andersons, 2007) do not solve problems associated with destruction at the micro level. It seems to us that it is more accurate to establish real mechanisms and deformation of fractures and take them into account in theoretical models (Reifsnider \& Stinchcomb, 2005; Chatys, 2013) for determining the strength of composites.

The basic methods of non-destructive testing of composites include ultrasonic, thermovision, radiological, 
visual, penetration, eddy current, acoustic emission, resonance and optical vibrations. In the research described in this work, the method of acoustic emission was proposed, which is very sensitive to fracture mechanisms at the micro level (Urbahs et al., 2010; Urbahs et al., 2012). The growing demand of the aviation industry for composite materials has led to intensive developement of technologies concerning composite materials, including the non-destructive testing area. Therefore, SAE and ASTM standards cover these tests on composites in aerospace applications, including the acoustic emission method Table 1 (Nowacki \& Sieczkiewicz, 2018).

The method of acoustic emission is characterized by high detection sensitivity and can be used to monitor the state of material structure in real time. This method allows detecting and tracking the development of damage to both the reinforcement and matrix of the composite, taking into account the state of the boundary layer between its components. The characteristics of the acoustic emission allow to estimate the damage accumulation and their intensity. The development of methods for analyzing acoustic signals in recent years has enabled the development of models assigning such recorded signals to indi-

Table 1. List of standards for testing of composites by the method of acoustic emission and general purpose standards

\begin{tabular}{|c|c|}
\hline Standard number & Standard title \\
\hline \multicolumn{2}{|c|}{ Acoustic emission method } \\
\hline $\begin{array}{l}\text { AST M E1495/ } \\
\text { E1495M-12 }\end{array}$ & $\begin{array}{l}\text { Standard Guide for Acousto-Ultrasonic } \\
\text { Assessment of Composites, Laminates, } \\
\text { and Bonded Joints }\end{array}$ \\
\hline $\begin{array}{l}\text { AST M E2191/ } \\
\text { E2191M-16 }\end{array}$ & $\begin{array}{l}\text { Standard Practice for Examination of } \\
\text { Gas-Filled Filament-Wound Composite } \\
\text { Pressure Vessels Using Acoustic } \\
\text { Emission }\end{array}$ \\
\hline $\begin{array}{l}\text { AST M E2661/ } \\
\text { E2661M-15 }\end{array}$ & $\begin{array}{l}\text { Standard Practice for Acoustic Emission } \\
\text { Examination of Plate-like and Flat } \\
\text { Panel Composite Structures Used in } \\
\text { Aerospace Applications }\end{array}$ \\
\hline PN-EN 15857:2010 & $\begin{array}{l}\text { Non-destructive testing - Acoustic } \\
\text { emission - Fiber reinforced polymer } \\
\text { testing - Specific methodology and } \\
\text { general criteria assessment (Polish } \\
\text { standard) }\end{array}$ \\
\hline \multicolumn{2}{|c|}{ General purpose standards } \\
\hline AST M E2533-16a & $\begin{array}{l}\text { Standard Guide for Nondestructive } \\
\text { Testing of Polymer Matrix Composites } \\
\text { Used in Aerospace Applications }\end{array}$ \\
\hline AST M E2981-15 & $\begin{array}{l}\text { Standard Guide for Nondestructive } \\
\text { Testing of the Composite Overwraps in } \\
\text { Filament Wound Pressure Vessels Used } \\
\text { in Aerospace Applications }\end{array}$ \\
\hline SAE ARP5606A & $\begin{array}{l}\text { Composite Honeycomb NDI Reference } \\
\text { Standards }\end{array}$ \\
\hline SAE ARP5605A & $\begin{array}{l}\text { Solid Composite Laminate NDI } \\
\text { Reference Standards }\end{array}$ \\
\hline
\end{tabular}

vidual composite destruction mechanisms (Kurzydłowski et al., 2005). Conducting such research is very important especially in the case of civil and military mobile objects such as cars, UAVs, airplanes, rockets or guided missiles (Koruba \& Nocoń, 2016). Practical tests in the field of acoustic susceptibility and damage assessment of composite structures were also conducted at the Institute of Aviation (Szafran et al., 2018). The article presents the results of experimental studies of samples made of fiberglass (Figure 1), the design feature of which is the presence in them of both base and weft fibers.

\section{The sample and test procedure}

Two groups were subjected to tensile testing (Figure 1).

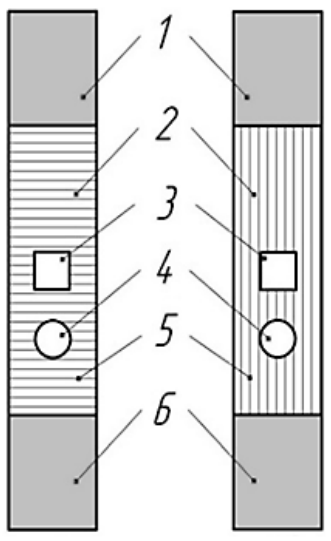

a)

b)

Figure 1. The sample

The first group included samples (Figure 1) on epoxy matrix (cut with a water-abrasive stream, not with plasma: Nowakowski \& Wijas, 2016) with a transverse arrangement of the base fibers relative to the applied force (Figure 1a); the second group included the same samples, but with a longitudinal orientation of the base fibers relative to the same applied force (Figure 1b). In addition, the second group of samples made of fiberglass also included a group of samples made of carbon fiber (on epoxy matrix). The samples (cut according to the standard DINEN ISO 527: length $250 \mathrm{~mm}$, width $25 \mathrm{~mm}$ and thickness from $1.92 \pm 0.1 \mathrm{~mm}$ to $2.2 \pm 0.02 \mathrm{~mm}$ - Figure 1) were rectangular plates 2 with plates 1 and 6 fixed to the upper and lower ends under the clamps of the traverse of the testing machine. Strain gauge 3 and acoustic emission sensor 4 were pre-glued on the samples. Figure 2 shows the switching circuit of the measuring complex used in these tests. For reliability and reliability of the results of acoustic emission studies, two different devices were used, operating from the same acoustic emission from sensor 2: acoustic emission of signals, device 10 , which is a recorder of signals of acoustic emission of signals with a bandwidth of $20 \mathrm{kHz}-2.0 \mathrm{MHz}$ and acoustic emission device 9, which allows you to record the parameters of acoustic emission signals in the frequency band from $1.0 \mathrm{kHz}$ to $1.0 \mathrm{MHz}$. 
For preliminary amplification of acoustic emission signals for a sensor mounting device 10 , preamplifier 8 with a gain of $40 \mathrm{~dB}$ in the frequency range from $20 \mathrm{kHz}$ to 2 $\mathrm{MHz}$ was used, and for instrument 9, preamplifier 7 with a gain of $26 \mathrm{~dB}$ in the frequency range from $100 \mathrm{kHz}$ to 1 $\mathrm{MHz}$. In the process of loading the samples with the device 10 , the total acoustic emission was recorded, with the device 9, the total acoustic emission, amplitude, intensity; energy and duration of the acoustic emission of signals were recorded.

The task of obtaining the dependence of signal changes: acoustic emission directly during loading by device 10 was solved using data acquisition card 11. In addition to acoustic emission data, this map was fed with data from the strain gauge module 12 from strain gauges 3, which contained information on the loading force, the magnitude of the displacement of the piston, and deformation. A similar problem in instrument 9 was solved using its parametric input, to which data on the load from dynamometer 6 of loading system 5 were supplied. To prevent reception of false acoustic emission signals from the places of clamping of the sample in clamps 4 the traverse of the testing machine, the test procedure provided for preliminary compression of each sample in places where the upper 1 and lower 6 pads are fixed (Figure 1) with a force one and a half times the labor force of clamping the sample in the clamps of the traverse, at which Ohm is the static loading of the sample. In this case, the Kaiser effect, known in acoustic emission, is triggered at the clamping points, which made it possible to obtain all acoustic emission information only from the sample zone between the clamps, which undergoes destruction during static loading. The task of obtaining the dependence of signal changes: acoustic emission directly during loading by device 10 was solved using data acquisition card 11 .

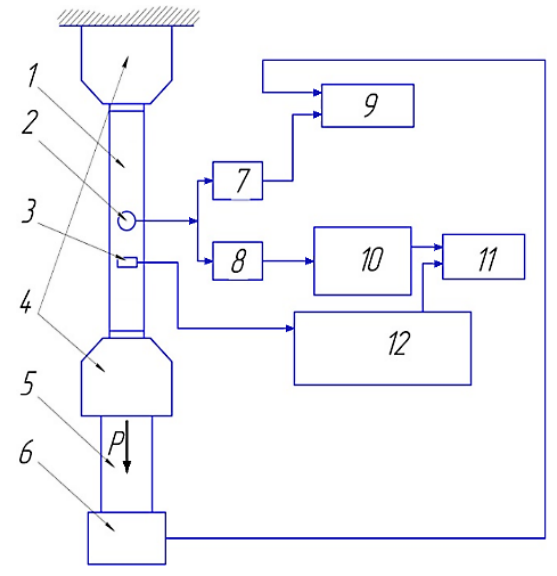

a)

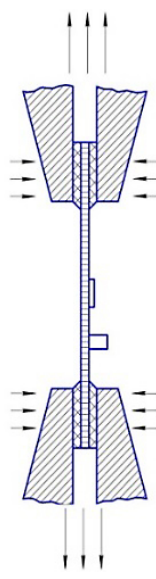

b)
Figure 2. The switching circuit of the measuring complex (a), the clamping pattern of the sample (b): 1 - sample; 2 - acoustic emission sensor; 3 - strain gauge; 4 - clamp; 5 - loading system; 6 - dynamometer; 7 and 8 - preamps; 9 - acoustic emission device; 10 - acoustic emission device; 11 - a data collection card; 12 - strain gauge module
In addition to acoustic emission data, this map was fed with data from the strain gauge module 12 from strain gauges 3 , which contained information on the loading force, the magnitude of the displacement of the piston, and deformation. A similar problem in instrument 9 was solved using its parametric input, to which data on the load from dynamometer 6 (Figure 2) of loading system 5 were supplied. To prevent reception of false acoustic emission signals from the places of clamping of the sample in clamps 4 (Figure 2) the traverse of the testing machine, the test procedure provided for preliminary compression of each sample in places where the upper 1 and lower 6 pads are fixed (Figure 1) with a force one and a half times the work force of clamping the sample in the clamps of the traverse, at which Ohm is the static loading of the sample. In this case, the Kaiser effect, known in acoustic emission, is triggered at the clamping points, which made it possible to obtain all acoustic emission information only from the sample zone between the clamps, which undergoes destruction during static loading.

\section{Test results of fiberglass samples}

For the convenience of analysis and comparative evaluation of test results, the graph data (Figures 4-7) are presented in relative units and the concept of staging is used (Urbahs et al., 2011, Prostaks \& Urbaha, 2019). Damage accumulation that allows you to recognize subtle phenomena of the nature of the destruction of fiberglass. When testing samples with a transverse arrangement of the base fibers with respect to tensile strength (Figure 3), a twostage nature of the composite deformation was revealed both in the deformation parameters (sections I and II) and in the parameters of the total acoustic emission ( $\mathrm{I}^{1}$ and $\left.\mathrm{II}^{1}\right)$ : the stage of proportional change of these parameters from voltage (sections $\mathrm{I}_{\text {and }} \mathrm{I}^{1}$ ) and the stage of their intensive increment, characterizing the beginning of the process of irreversible destruction of the composite (II and $\left.\mathrm{II}^{1}\right)$.

Both curves, both in the deformation parameters and in the parameters of acoustic emission, are similar to the deformation curve characterizing the behavior of a pure matrix, i.e. matrices with a zero volume fraction of fibres and the absence of weft fibres, having strictly, as can be seen from the figure, a stage of elastic deformation and a stage of fluidity. In our case, the presence of weft fibres along which the loading process takes place leads to a redistribution of the load, part of which is perceived by the weft fibres themselves, and the other falls on the matrix, thereby eliminating the stage of pure fluidity and, as can be seen from Figure 4, the process of irreversible deformations (the $2^{\text {nd }}$ stage of fracture of the composite) begins with approximately 0.8 of the breaking stress in the deformation parameter (boundary of sections 1 and 2) and with 0.75 of the breaking stress in the parameter of total acoustic emission (boundary of sections $1^{1}$ and $2^{1}$ ) And since in this case the warp fibres are practically not 


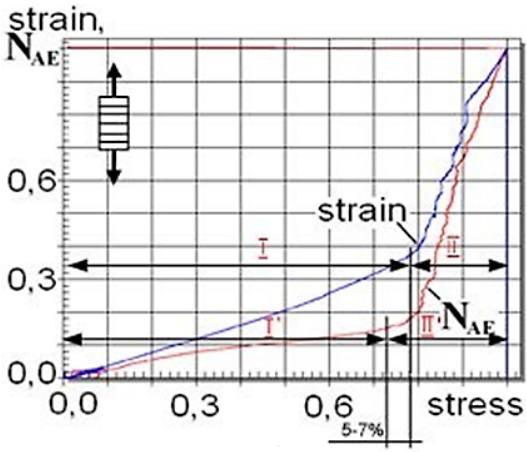

a)

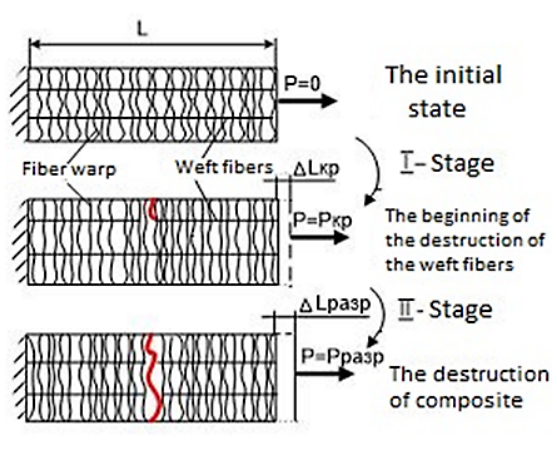

b)

Figure 3. Schedule of changes in the total acoustic emission and deformation from stress (a) and the proposed mechanism for the destruction of the composite in the transverse arrangement of the fibres of the base relative to the tensile force (b)

loaded, this kind of fracture is characteristic of the partial destruction of the composite matrix, i.e. epoxy resin, and partially weft fibres. Thus, in the first stage of loading, weft fibres are tensioned, which participate in the redistribution of the load on the matrix within the elastic deformation. At the second stage, the strength of a weft fibres or a group of fibres is exhausted. The deformation parameter does not yet respond to this, but the intensity of the increment of the total acoustic emission begins to increase. With further loading, the load is sequentially redistributed to the remaining undamaged weft fibres, which leads to a further loss of strength of one or a group of them. The intensity increment of the total acoustic emission continues to increase. A further increase in the load is apparently caused by the self-destruction process. From this moment, the strain parameter, which, as can be seen from Figure 3, begins to grow more intensively than the load. A rapid increment of both parameters occurs up to the complete destruction of the sample cross section. Therefore, the process of the beginning of the destruction of the composite with this type of loading is actually detected by acoustic emission data by $5-6 \%$ earlier than the strain parameter indicates, which was confirmed by subsequent tests. The effect of training on the mechanical properties of a batch of samples with three-time training characterizes the graph shown in Figure 4. It can be seen that the whole process is similar to the previous test result: there are sections of proportional changes in the deformation parameters and total acoustic emission from stress and a section of their intensive increment, as well as in the first case, characterizing the beginning of the process of irreversible fracture of the composite. However, the beginning of irreversible destruction processes occurs earlier (starting from approximately 0.7 from the destructive stress in the deformation parameter and from 0.65 from the destructive stress in the parameter of total acoustic emission). It can be seen that training the sample reduced the onset of irreversible fracture by about $10 \%$.

The test results of samples with a longitudinal arrangement of fibres along the tensile force are presented in Fig- ure 5 on the right, which shows graphs of the dependence of deformation and total acoustic emission on stress in the cross section of the sample under static loading.

For the convenience of analysis and comparative evaluation of test results, the graph data are also presented, as in the previous case, in relative units. It can be seen that the entire loading process in the deformation parameters (Figure 6a, strain curve) has an almost straightforward relationship. But the nature of the changes in the total acoustic emission has a pronounced staging, which can be divided into three stages:

$1^{\text {st }}$ stage - the stage of initial intensive growth of total acoustic emission;

$2^{\text {nd }}$ stage - the stage of stabilization of the total acoustic emission;

$3^{\text {rd }}$ stage - the stage of secondary intensive growth of total acoustic emission up to destruction.

All three stages form a single S-shaped form of changes in the total acoustic emission. Thus, by the nature of the change in the total acoustic emission, one can judge the staged process of microdestruction, which cannot be done by deformation parameters. Such a character of S-shaped behavior in the behavior of the total acoustic emission is observed in all samples without exception with a longi-

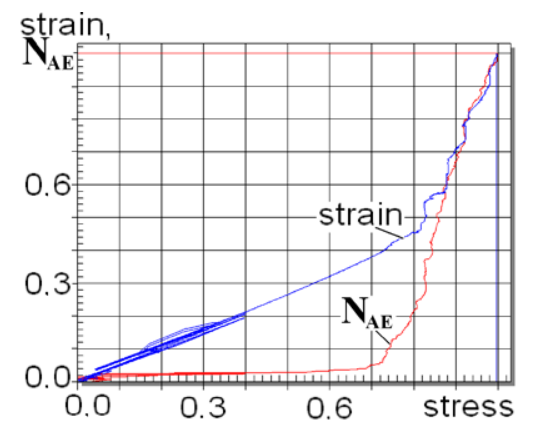

Figure 4. The dependence of the total acoustic emission and deformation on the stress of the sample with a transverse arrangement of fibres with three times training, corresponding to $40 \%$ of the breaking load (sample width $20 \mathrm{~mm}$ ) 
a)

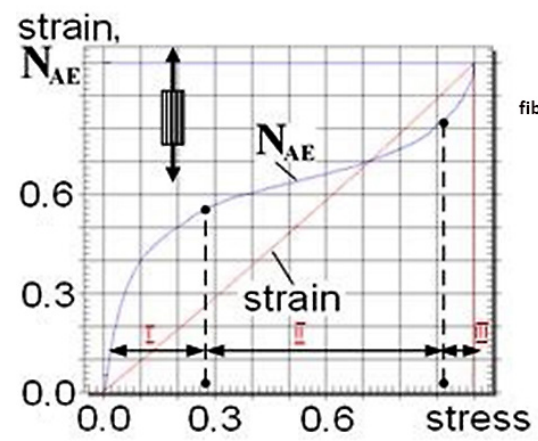

a) b)

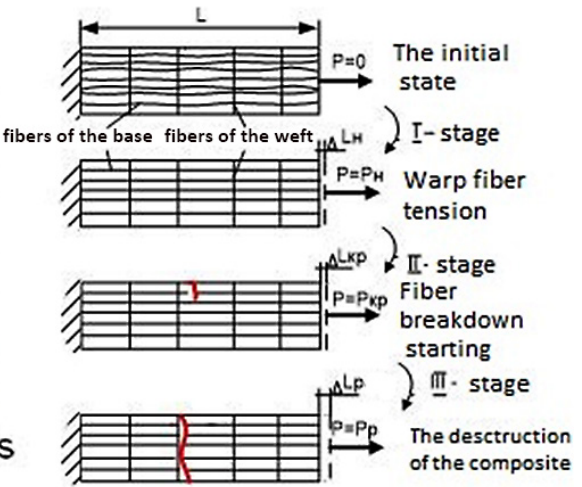

b)

Figure 5. Schedule of changes in the total acoustic emission and deformation from stress (a) and the proposed mechanism for the destruction of the composite in the

longitudinal arrangement of the fibres of the base relative to the tensile force (b)

tudinal direction of the fibers with respect to the applied load.

The proposed mechanism of composite destruction in this case is clearly illustrated by the circuit shown in Figure $5 \mathrm{~b}$ (right), corresponding, as indicated above, to the three-stage nature of the deformation, which shows the loading of the sample in the following sequence:

- from the initial state of the sample of length $\mathrm{L}$, when the base fibres are not yet stretched, to the loading of $\mathrm{P}_{\mathrm{H}}$ with their corresponding tension to deformation $\Delta \mathrm{L}$ (1st stage). The intensive growth of total acoustic emission observed at this stage occurs mainly due to microcracking of the weak points of adhesion of the matrix to the base fibers;

- from the beginning of loading, in which all the fibers of the base completely begin to absorb the entire load on themselves until the critical loading of $\mathrm{P}_{\kappa \mathrm{p}}$, when one of the fibers of the base or a group of fibres is on the verge of loss of strength (stage 2). At this stage, the processes of microcracking are less weak, because they have passed mainly at the first stage, which affects the behavior of the total acoustic emission. It changes at this stage more hollow;

- from the beginning of loading, when one of the base fibres or a group of fibres lose their strength, until loading $\mathrm{P}_{\mathrm{p}}$, in which the composite is completely destroyed (stage 3 ). At this stage, through the matrix, the load is sequentially redistributed to the remaining undamaged base fibers, and an increase in load leads to a further loss of strength of the next weakest fiber. The intensity increment of the total acoustic emission begins to increase. With further loading, the process of self-similarity of sequential destruction of the base fibres begins, which causes further rapid growth in the total acoustic emission. In this case, the deformation parameter continues its uniform growth and practically does not respond to any stage of fragmen- tary loss of strength of the composite until its complete destruction. The influence of training equal to $20 \%$ of the breaking load does not significantly affect the nature of the "S-shape" of the total acoustic emission (Figure 6a), and as you can see the shape of the "S-shape" is preserved, but the stage of stable change in the total acoustic emission is reduced, as well as the stage of the secondary rapid change in the total acoustic emission before destruction, while the third stage is even more intense than without training.

Further testing of the samples during training less than $20 \%$ of the breaking load showed that the shape of the S-shape remains, both with a different number of workouts and with a change in the width of the samples, although strain gauging in these cases gives a straightforward dependence on stress (just like in the case without training strain). However, acoustic emission shows that the three-time training process (Figure 6a) and the sixtime training process (Figure 6b) leaves its mark in the form of the Kaiser effect (horizontal sections of the total acoustic emission curve). However, starting from 35\% of the destructive load, the training affects the behavior of the total acoustic emission (Figure 6b). The Kaiser effect is not preserved, the destruction process becomes two-stage and the main part of the process falls on the first stage.

Conducting tests on a large number of samples by acoustic methods allows determining the distribution of damage in composite structures. It is important for fatigue durability of cyclically loaded elements of aircraft structures (Szafran \& Delas, 2018).

For comparison, an example of other tests conducted using the acoustic emission method can be given (Świt \& Adamczak, 2015). The composite based on E-type glass fibers arranged parallely and epoxy resin with $72 \%$ filling was stretched there. The Young's modulus of the composite tested was about $42 \mathrm{GPa}$. The tests were performed on tensile samples with dimensions of $1.5 \times 20 \times 200 \mathrm{~mm}$. 


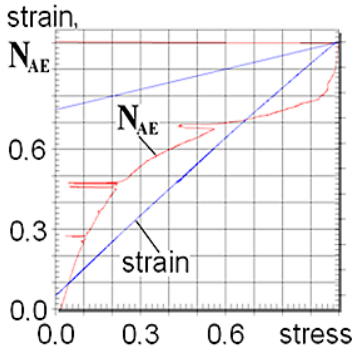

a)

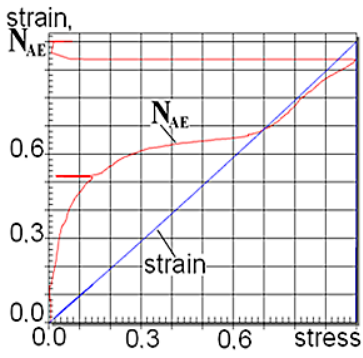

b)

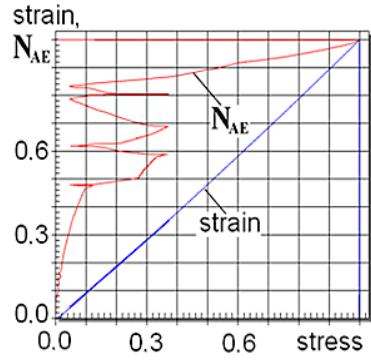

c)

Figure 6. The dependence of the total acoustic emission and deformation on the stress of the sample with a longitudinal arrangement of fibres: a - with triple training $20 \%$ of the breaking load (sample width $20 \mathrm{~mm}$ ); b - with a six-time training 15\% of the breaking load (sample width $30 \mathrm{~mm}$ ); $\mathrm{c}$ - with triple training $38 \%$ of the breaking load (sample width $30 \mathrm{~mm}$ )
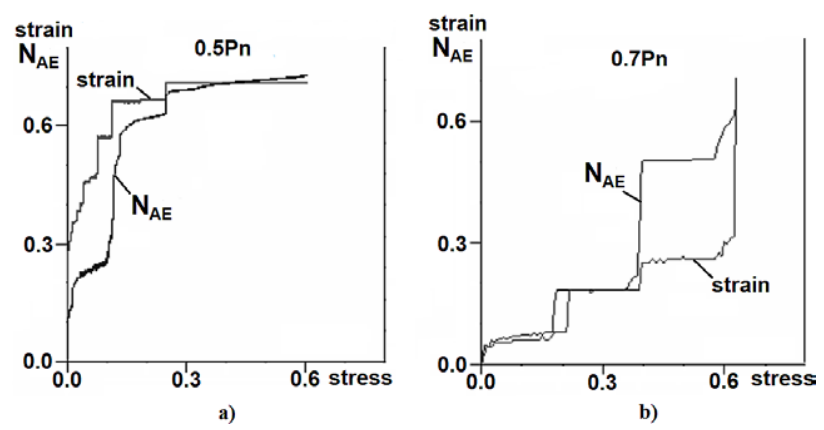

Figure 7. The results of acoustic tests for load of $0.5 \mathrm{Pn}$ (a) and $0.7 \mathrm{Pn}(\mathrm{b})$

The average destructive force of the composite was $\mathrm{Pn}=$ $10 \mathrm{kN}$. Acoustic measurements were carried out at two load levels equal to $0.5 \mathrm{Pn}$ and $0.7 \mathrm{Pn}$. The results are shown in Figures $7 \mathrm{a}$ and $7 \mathrm{~b}$.

It can be seen that the sudden increase in the sum of events during loading is accompanied by an increase in displacement combined with the fracture of individual composite fibers and an increase in stress in the tested sample. The graphs show that changes in the composite features are in this case a discrete process and occur rapidly, which is characteristic of brittle materials. If the change in elongation occurs in a stable manner, the number of $\mathrm{AE}$ signals does not increase rapidly. It follows that the increases in emission and displacement signals are interconnected.

Figure $7 \mathrm{a}$ shows that at $0.5 \mathrm{Pn}$ in the first stage of composite work, the increase in $\mathrm{AE}$ signals and displacement is continuous and linear. As the time of force exposure increases, the process begins to run abruptly, although the intensity of this process is not high. At a composite load of $0.7 \mathrm{Pn}$ (Figure $7 \mathrm{~b}$ ), the stress corrosion process, looking at the displacement and $\mathrm{AE}$ signals diagram, is non-linear, discontinuous and the jumps in changes of recorded parameters are clearly visible.

\section{Conclusions}

1. A feature of the tests, the results of which are presented in the article, it is that in the tested samples the structure has the fibres warp and weft fibres. Samples were tested with a transverse and longitudinal arrangement of the load to the fibres. The tests have shown:

1.1. For samples with a transverse arrangement of fibres with respect to the applied load, the fracture process both in the deformation parameters and in the parameters of the total $\mathrm{AE}$ has two stages of damage accumulation: the stage of proportional change of these parameters from voltage and the stage of intensive increment of these parameters. In this case, the total $\mathrm{AE}$ parameter shows that this fracture process begins earlier by $5-6 \%$ than the deformation parameter shows.

1.2. The nature of the change in the total AE for samples with a longitudinal arrangement of fibres with respect to the applied load shows that the fracture process in this case consists of three stages of damage accumulation, which cannot be seen from the deformation parameters.

2. The test results of the samples "received" a preliminary training show that:

2.1. For samples without training or with training up to $20 \%$ of the breaking load, the "S-shaped" form of behavior of the total $\mathrm{AE}$ is preserved in all samples without exception, characterizing the three-stage process of damage accumulation. In this case, triple and sixfold training at low loading values (up to $20 \%$ of the breaking load) has a weak effect on the behavior of the curve of the total AE.

2.2. Three-time training at high values of loading (with $35 \%$ of the breaking load) has a strong influence on the behavior of the curve of the total AE, and the process of damage accumulation takes a two-stage nature.

2.3. Under the given loading conditions, the strength of the samples does not affect the tensile strength.

3 . The methodology and equipment proposed by the authors allows to identify the nature of fracture and evaluate the tensile strength of the "staged" composition of samples, and also to solve the problem of what affected the structural unity violations, which may be caused by the presence of a set of cracks formed during manufacturing or under the influence of stresses and external environment during loading. 
4. Disadvantages of the proposed test method:

4.1. Low sensitivity to damage of constant size.

4.2. The ability to analyze measurements only by means of specialized software by an experienced operator.

4.3. High sensitivity of the acoustic emission test system to noise.

5. As the advantages of the acoustic emission method can be considered:

5.1. The possibility of comprehensive inspection of large elements and structures.

5.2. Possibility of locating the source of AE signals generated by defects or damage.

5.3. The ability to monitor processes at the time and place of their occurrence.

5.4. Advantage over other non-destructive methods is that the element can be tested continuously in its normal operating conditions (especially under load) and the possibility of detection of increasing defects.

6. Sample training does not affect tensile strength under these load conditions.

\section{References}

Chatys, R. (2013). Investigation of the effect of distribution of the static strength on the fatigue failure of a layered composite by using the Markov Chains Theory. Mechanics of Composite Materials, 48(6), 629-638.

https://doi.org/10.1007/s11029-013-9307-9

Koruba, Z., \& Nocoń, Ł. (2016). Numerical analysis of dynamics of an automatically tracked anti-tank guided missile using polynomial functions. Journal of Theoretical and Applied Mechanics, 54(1), 13-25. https://doi.org/10.15632/jtam-pl.54.1.13

Kurzydłowski, K. J., Boczkowska, A., Shmidt, J., Konopka, K., \& Spychalski, W. (2005). Monitoring of failures in the composites by non-destructive methods (in Polish). Polimery, 50(4), 255-261. https://doi.org/10.14314/polimery.2005.255

Mortensen, A. (2007). Concise encycloped of composite materials (2nd ed.). Elsevier.

Myers, T. J., Kytömaa, H. K., \& Smit, T. R. (2007). Environmental stress-corrosion cracking of fiberglass: lessons learned from failures in the chemical industry. Journal of Hazardous Materials, 142(3), 695-704.

https://doi.org/10.1016/j.jhazmat.2006.06.132

Nowacki, J., \& Sieczkiewicz, N. (2018). Advances in NDT assessment of the quality of polymer composites in production conditions (in Polish). Nondestructive Testing and Diagnostics, $1,11-17$.

Nowakowski, L., \& Wijas, M. (2016). The evaluation of the process of surface regeneration after laser cladding and face milling. In I. Zolotarev \& V. Radolf (Eds.), Proceedings of 22th International Conference Engineering Mechanics 2016 (pp. 430-433). Institute of Thermomechanics, The Czech Academy of Science, Prague.

Paramonov, Yu., \& Andersons, J. (2007). A family of weakest link models for fibre strength distribution. Composites part A: Applied Science and Manufacturing, 38(4), 1227-1233. https://doi.org/10.1016/j.compositesa.2006.06.004

Parratt, N. J. (1960). Defects in glass fibers and their effects on the strength of plastic mouldings. Rubber and Plastics Age, March 1960.

Prostaks, J., \& Urbaha, M. (2019). Evaluating accuracy of fault localization when monitoring condition of large structures by acoustic method. In Contents of Proceedings of 18th International Scientific Conference Engineering for Rural Development, 18, 1280-1286.

https://doi.org/10.22616/ERDev2019.18.N143

Reifsnider, K. L., \& Stinchcomb, W. W. (2005). A critical-element model of the residual strength and life of fatigue-loaded composite coupons. In H. H. Thomas, Composite Materials: Fatigue and Fracture (pp. 298-313). ASTM International. https://doi.org/10.1520/STP19992S

Roy, R., Kweon, J., \& Choi, J. H. (2014). Meso-scale finite element modeling of Nomex ${ }^{\mathrm{TM}}$ honeycomb cores. Advanced Composite Materials, 23(1), 17-29.

https://doi.org/10.1080/09243046.2013.862382

Shanley, F. (1962). Historical note on the 1.5 factor of safety for aircraft structures. Journal of the Aerospace Sciences, 29(2), 243-244. https://doi.org/10.2514/8.9385

Szafran, K., Krzymień, W., \& Cieślak, S. (2018). Acoustic characteristics of the cabin of the research platform on the Airbag IL-PRC- 600M. Transaction on Aerospace Research, 2(251), 16-29. https://doi.org/10.2478/tar-2018-0012

Szafran, K., \& Delas, N. (2018). Accumulation of fatigue microdefects - entropy interpretation. Fatigue of Aircraft Structures. 2018(10), 104-116. https://doi.org/10.2478/fas-2018-0010

Świt, G., \& Adamczak, A. (2015). Stress corrosion of epoxy-glass composites monitored using acoustic emission (in Polish). TTS Technika Transport Szynowego, 22(12), 1531-1534.

Urbahs, A., Banovs, M., Harbuz, Y., Turko, V., Feščuks, J., \& Khodos, N. (2010, 5-9 July). Estimation of mechanical properties of the anisotropic reinforced plastics with application of the method of acoustic emission [Conference presentation abstracts]. The 2nd International Specialized Symposium "Space \& Global Security of Humanity” (p. 93). Latvia, Riga.

Urbahs, A., Banovs, M., Turko, V., \& Feshchuk, Y. (2012, 26-27 April). New approach to use the acoustic emission monitoring for the defects detection of composit-material's design elements. In Water Transport and Infrastructure: 1. International Conference (pp. 45-50). Latvia, Riga.

Urbahs, A., Banovs, M., Turko, V., Feshchuk, Y., \& Khodos, N. (2011, 11-15 July). Investigation of micromechanics of plasto-elastic behaviour of anisotropic composite materials under static loading by the acoustic emission method. In Advances and Trends in Engineering Materials and Their Applications: Conference Proceedings. Latvia, Riga. 